\title{
Colchicine - From rheumatology to the new kid on the block: Coronary syndromes and COVID-19
}

\author{
Stanisław Surma ${ }^{1}$, Marcin $\operatorname{Basiak}^{1}{ }^{1}$, Monika Romańczyk $^{1}{ }^{\oplus}$, \\ Krzysztof J. Filipiak ${ }^{2}$ (D), Bogusław Okopień ${ }^{1}$ (1) \\ ${ }^{1}$ Department of Internal Medicine and Clinical Pharmacology, \\ Medical University of Silesia, Katowice, Poland \\ ${ }^{2}$ Department of Clinical Sciences, Maria Sklodowska-Curie Medical Academy, Warsaw, Poland
}

\begin{abstract}
Colchicine is an effective anti-inflammatory agent used to treat gout, coronary artery disease, viral pericarditis, and familial Mediterranean fever. It has been found to act by preventing the polymerization of the protein called tubulin, thus inhibiting inflammasome activation, proinflammatory chemokines, and cellular adhesion molecules. Accumulating evidence suggests that some patients with coronavirus disease 2019 (COVID-19) suffer from "cytokine storm" syndrome. The ideal anti-inflammatory in this setting would be one that is readily available, cheap, orally administered, with a good safety profile, well-tolerated, and that prevents or modulates inflammasome activation. The researchers selected colchicine for their study. This paper is a review of the literature describing the effects of colchicine, which is a drug that is being increasingly used, especially when standard therapy fails. Colchicine was shown to reduce inflammatory lung injury and respiratory failure by interfering with leukocyte activation and recruitment. In this publication, we try to systematically review the current data on new therapeutic options for colchicine. The article focuses on new data from clinical trials in COVID-19, rheumatic, cardiovascular, and other treatment such as familial Mediterranean fever, chronic urticaria, and PFAPA syndrome (periodic fever, aphthous, stomatitis, pharyngitis, and cervical adenitis). We also summarize new reports on the side effects, drug interactions, and safety of colchicine. (Cardiol J 2023; 30, 2: 297-311)
\end{abstract}

Key words: colchicine, rheumatic diseases, cardiovascular diseases, COVID-19

\section{Colchicine: Mechanism of action}

Colchicine (Central illustration) is a strong plant alkaloid with a toxic effect, used in herbal medicine, obtained from the seeds of the autumn winter plant (Colchicum autumnale).

Colchicine in doses of $1 \mathrm{mg} / \mathrm{kg}$ body weight is fatal, but at therapeutic doses it is characterized by pleiotropic effects $[1,2]$. Colchicine is commonly used in the treatment of gout, familial Mediterranean fever (FMF), Behçet's disease, pericarditis, coronary artery disease (CAD), and other inflammatory diseases $[1,2]$. Colchi- cine has multiple mechanisms of action (Fig. 1) [1-4].

The best known mechanisms of action of colchicine are inhibition of microtubule polymerization (at a low dose) or stimulation of microtubule depolymerization (at a higher dose) [5, 6]. Microtubules are a key component of the cytoskeleton and are involved in many cellular processes such as maintaining cell shape transfer of intracellular substances, secretion of cytokines and chemokines, cell migration, regulation of ion channels, and cell division [1]. Colchicine is an antimitotic agent that blocks cell division during metaphase $[5,6]$.

Address for correspondence: Marcin Basiak, MD, PhD, Department of Internal Medicine and Clinical Pharmacology, Medical University of Silesia in Katowice, ul. Medyków 18, 40-752 Katowice, Poland, tel: +48 3225239 02, fax: +48 322523902 , e-mail: mbasiak@sum.edu.pl

Received: 7.08.2021 Accepted: 27.08.2021 Early publication date: 8.10.2021

This article is available in open access under Creative Common Attribution-Non-Commercial-No Derivatives 4.0 International (CC BY-NC-ND 4.0) license, allowing to download articles and share them with others as long as they credit the authors and the publisher, but without permission to change them in any way or use them commercially. 


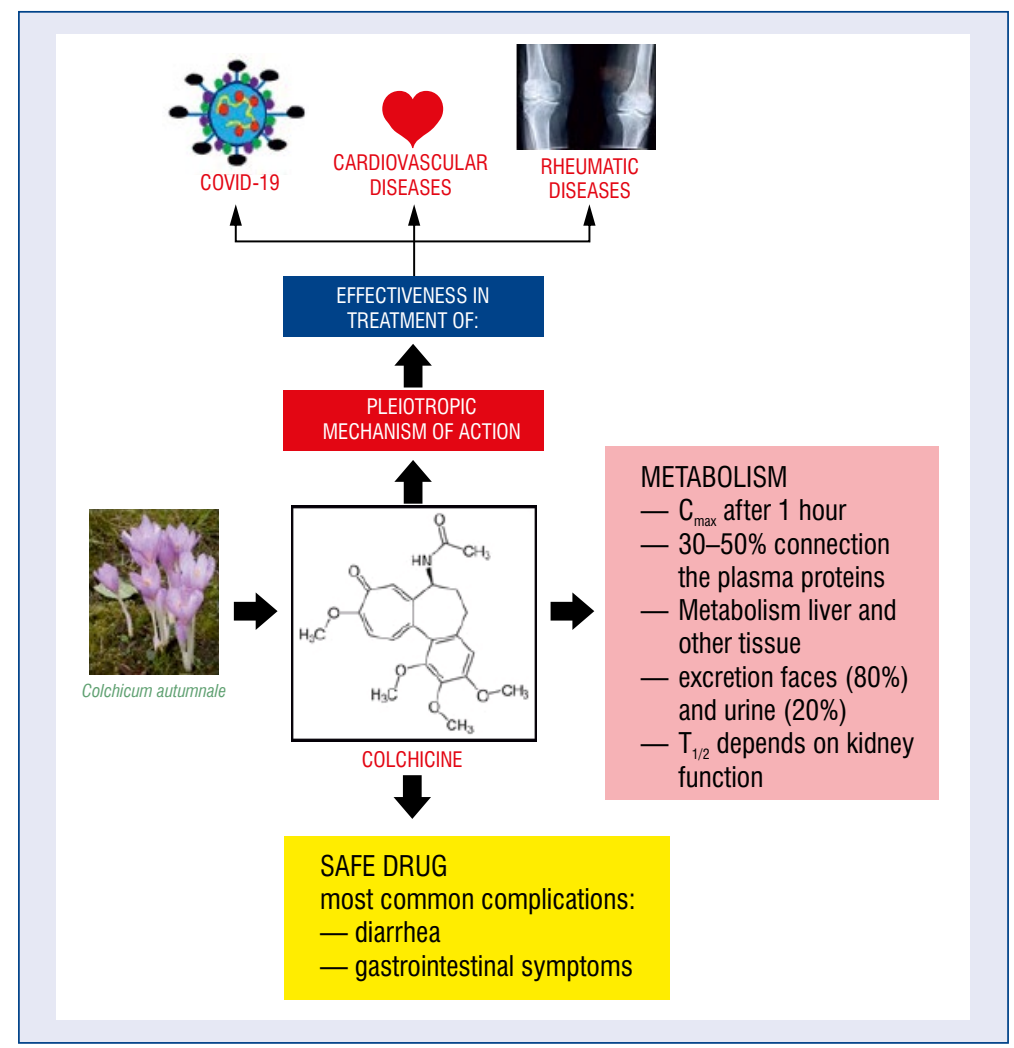

Central illustration. Colchicine is obtained from Colchicum autumnale and is characterized by anti-inflammatory, immunomodulatory, and antimicrotubular properties. It also reduces uric acid levels. Colchicine is used in the treatment of rheumatic diseases, cardiovascular diseases, and recently also coronavirus disease 2019 (COVID-19).

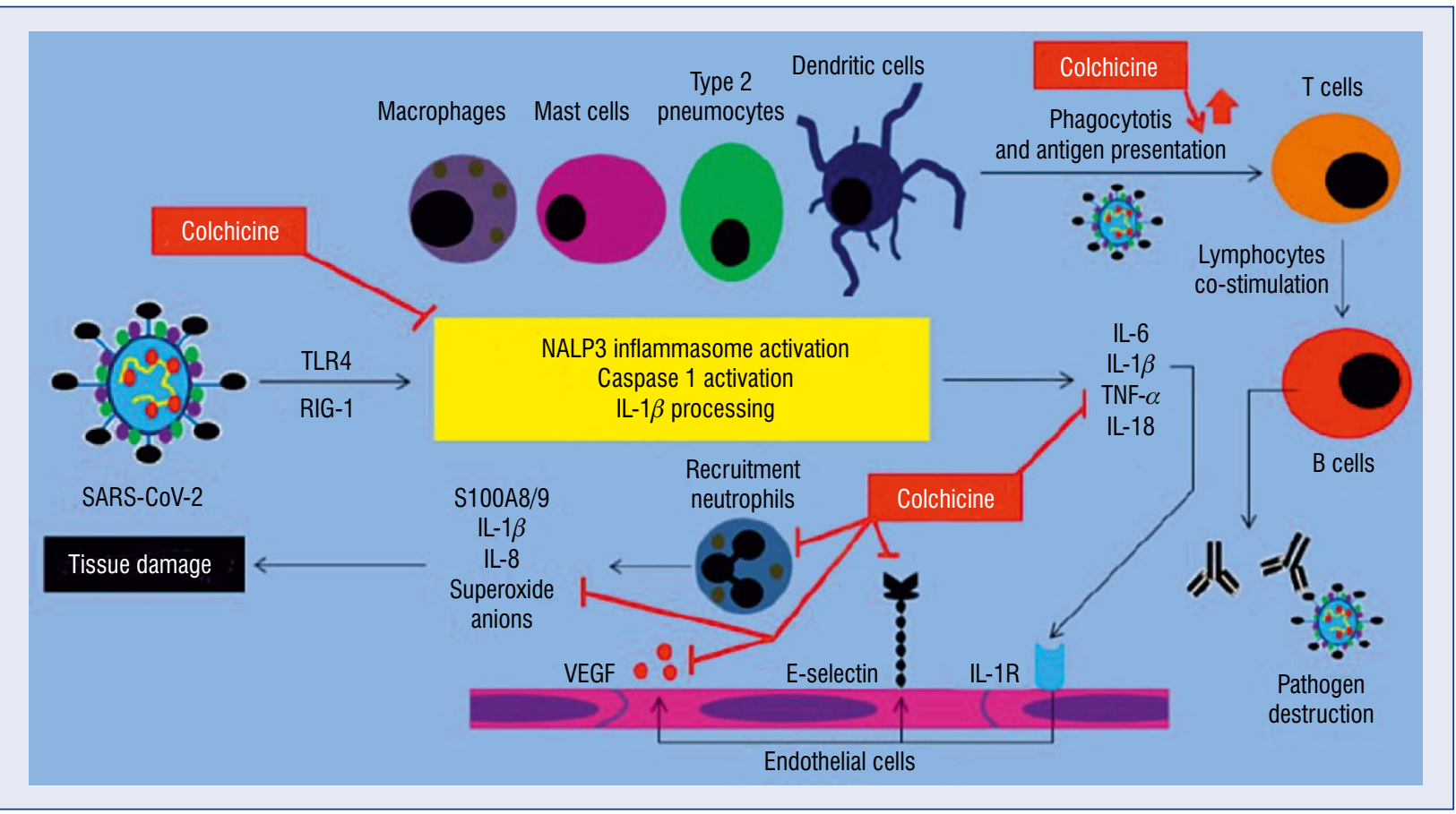

Figure 1. Mechanism of action of colchicine with regard to its potential role in the treatment of coronavirus disease 2019 (COVID-19) [1-4]; TLR4 - toll-like receptor 4; RIG-I — retinoic acid-inducible gene I; NALP3 - NACHT, LRR, and PYD domains-containing protein 3; IL-1 $\beta$ - interleukin 1beta; IL-6 — interleukin 6; IL-18 — interleukin 18; IL-1R — interleukin-1 receptor; TNF- $\alpha$ — tumor necrosis factor alpha; VEGF — vascular endothelial growth factor. 
In addition to the primary microtubule mechanism of action of colchicine, its anti-inflammatory and immunomodulatory properties encompass several other pathways. Colchicine in small doses reduces the level of E-selectin on vascular endothelial cells, which prevents the neutrophils from sticking to its surface. Colchicine in higher doses promotes elimination L-selectin from neutrophils, preventing these cells from interacting with the vascular endothelium [1]. Moreover, colchicine inhibits the activation of innate immunity, the so-called NALP3 inflammasome activation (severe acute respiratory syndrome coronavirus 2 [SARS-CoV-2] stimulates the NALP3 inflammasome), activates caspase 1 , and inhibits chemotactic release factor from neutrophils, thereby reducing the subsequent recruitment of neutrophils to various tissues [5]. Colchicine inhibits the activation and release of interleukin 1 (IL-1) and interleukin 8 (IL-8) as well as superoxide from neutrophils [7]. An important mechanism of action of colchicine is to stimulate the maturation of dendritic cells, which then become antigen presenting cells [1]. In addition, colchicine inhibits vascular endothelial growth factor (VEGF), which reduces the proliferation of vascular endothelial cells [1]. Interestingly, a study in rats showed that colchicine reduced the release of tumor necrosis factor alpha (TNF- $\alpha$ ) by lipopolysaccharide-induced macrophages [8]. In the mouse brain macrophage cell line, colchicine inhibited adenosine triphosphate (ATP)-induced interleukin 1beta (IL-1 $\beta$ ) release by preventing microtubule rearrangement and limiting activation of the Ras homolog gene family, member A (RhoA) associate, which includes the protein kinase (ROCK) pathway [6]. In the presence of colchicine, murine peritoneal macrophages demonstrated lower ATPinduced permeability to ethidium bromide and less formation of reactive oxygen species (ROS), nitrogen oxide (NO), and release of IL- $1 \beta$ [8]. All these compounds increase the inflammatory process and are responsible for interstitial infiltration and lung collapse. Through the various mechanisms described above, colchicine can minimize such damage [1].

\section{Colchicine in the treatment of rheumatic diseases}

Gout

A randomized study by Terkeltaub et al. [9] in 184 patients with acute gout assessed the effects of large ( $4.8 \mathrm{mg}$ total over $6 \mathrm{~h} ; \mathrm{n}=52$ ) and small (1.8 $\mathrm{mg}$ total over $1 \mathrm{~h} ; \mathrm{n}=74$ ) doses of colchicine or placebo $(n=58)$ for a pain reduction of $\geq 50 \%$ after 24 hours without rescue treatment. It was shown that pain relief in the first 24 hours was administered by $23(31.1 \%)$ patients in the low-dose group ( $\mathrm{p}=0.027$ vs. placebo), $18(34.6 \%)$ patients in the high-dose group ( $\mathrm{p}=0.103$ compared to placebo), and $29(50.0 \%)$ patients in the placebo group. There was no statistically significant difference in the incidence of adverse events between low-dose colchicine and placebo (odds ratio [OR] 1.5 ; $95 \%$ confidence interval [CI] 0.7-3.2). Thus, it was deduced that the use of low doses of colchicine allows for effective prevention of pain attacks during gout exacerbation [9].

The safety and efficacy of naproxen and low-dose colchicine in the treatment of gout attacks were analyzed in a randomized trial by Roddy et al. [10]. Adults with a gout flare recruited from 100 general practices were randomized equally to naproxen $750 \mathrm{mg}$ immediately then $250 \mathrm{mg}$ every 8 hours for 7 days or low-dose colchicine $500 \mathrm{mg}$ 3 times per day for 4 days. The study included 399 people, 200 of whom were taking naproxen and 199 were taking colchicine. There was no significant between-group difference in average pain-change scores over days 1-7 (colchicine vs. naproxen: mean difference $-0.18 ; 95 \% \mathrm{CI}-0.53$ to $0.17 ; \mathrm{p}=$ $=0.32$ ). During days $1-7$, diarrhea $(45.9 \%$ vs. $20.0 \%$; OR 3.31; 95\% CI 2.01-5.44) and headache (20.5\% vs. $10.7 \%$; OR 1.92 ; 95\% CI 1.03-3.55) were more common in the colchicine group than in the naproxen group, but constipation was less common (4.8\% vs. $19.3 \%$; OR $0.24 ; 95 \%$ CI $0.11-0.54$ ). Thus, there was no difference in pain intensity over the 7 days between individuals with a gout flare-up who were randomized to either naproxen or low-dose colchicine. Naproxen caused fewer side effects, supporting naproxen as the first-line treatment of gout flares in primary care with no contraindications [10]. Based on the results of this study, it can be concluded that naproxen may be a good alternative to colchicine in patients with contraindications to its use or in people taking medications that may interact with it. Naproxen is mainly excreted unchanged, and to some extent it is metabolized by CYP1A2 and CYP2C9 (in contrast to colchicine metabolized by CYP3A4).

\section{Osteoarthritis of the knee}

In a randomized study, Aran et al. [11] assessed the effect of colchicine administration on the course of osteoarthritis of the knee. The study included 61 postmenopausal patients with primary osteoarthritis of the knee, who were randomized 
into two groups receiving $0.5 \mathrm{mg}$ of colchicine $2 \times /$ day or placebo. As an analgesic, acetaminophen in a dose less than $2 \mathrm{~g}$ /day was used. It was shown that the use of acetaminophen was significantly lower in the colchicine group $(879.3 \pm 369.7)$ compared to the placebo group $(1620.7 \pm 393.1$; $p=0.000)$. The rate of improvement at the end of 3 months was significantly greater in the colchicine group for both patient global assessment and the physician's overall assessment measures compared to the placebo group (11.14 \pm 4.06 vs. $3.14 \pm 2.18, \mathrm{p}=0.000$ and $9.83 \pm 3.799$ vs. $3.72 \pm$ $\pm 3.35, \mathrm{p}=0.000)$. Thus, this study demonstrated the effectiveness in reducing pain in patients with osteoarthritis of the knee [11]. In a study by Erden et al. [12], involving 60 patients with osteoarthritis of the knee joint, the impact of adding colchicine to paracetamol therapy on the course of the disease and total antioxidant capacity was assessed. Patients were assigned to receive only paracetamol (3 g/day) or paracetamol (3 g/day) + colchicine $(1.5 \mathrm{~g}$ /day) for 6 months. It was shown that the clinical parameters assessed using the WOMAC scale (Western Ontario and McMaster Osteoarthritis Index) improved significantly in patients using colchicine $(p>0.05)$. The total antioxidant capacity increased only in the colchicine group. In both groups the concentration of malondialdehyde was significantly reduced. The activities of enzymes: catalase, superoxide dismutase, and glutathione concentration did not change in both groups of patients. Thus, it was found that colchicine reduces the concentration of malondialdehyde in the blood and increases the total antioxidant capacity in patients with osteoarthritis of the knee. This may indicate that colchicine has a modifying effect on the course of knee osteoarthritis [12]. Similar results were obtained by Leung et al. [13] in a randomized, placebo-controlled, double-blind clinical trial. The study included 109 patients with osteoarthritis of the knee, randomized to oral treatment with colchicine $0.5 \mathrm{mg}$ twice daily or placebo. It was shown that the intake of colchicine significantly reduced the mean serum concentration of highsensitivity C-reactive protein (hs-CRP; $\mathrm{p}=0.008$ ) and $\mathrm{C}$-terminal telopeptides of type I collagen $(p=0.002)$. In addition, treatment with colchicine tended to reduce serum levels of inflammatory markers such as IL-6, IL-8, TNF- $\alpha$, CD14, and IL-18, but these differences were not statistically significant. There was no reduction in osteoarthritis of the knee symptoms during the 16 -week study period. Thus, colchicine in this study reduced inflammation and high bone turnover biomarkers known to be associated with the severity and risk of degenerative disease progression but did not reduce symptoms [13].

A systematic review of the literature and a meta-analysis by Restrepo-Escobar et al. [14] attempted to evaluate the efficacy and safety of colchicine in the treatment of osteoarthritis of the knee (primary or related to the deposition of calcium pyrophosphate crystals). The review and meta-analysis included 5 randomized clinical trials involving 223 patients with osteoarthritis of the knee. Colchicine was shown to reduce pain intensity by at least $30 \%$ compared to control (OR 9.96; 95\% CI 2.29-43.36) and improved patient functioning (OR 8.92; 95\% CI 2.30-34.65). Thus, colchicine appears to be an effective and safe treatment alternative for adult patients with osteoarthritis of the knee, whether primary or related to calcium pyrophosphate crystal deposition. Its use reduced pain and improved the functioning of patients [14].

\section{Behçet's disease}

The efficacy of colchicine in the treatment of Behçet's disease was assessed in a randomized study by Davatchi et al. [15]. The study included 169 patients with Behçet's disease, who were randomized to take colchicine $(1 \mathrm{mg} /$ day) or placebo for 4 months. After 4 months, they were switched (colchicine to placebo, placebo to colchicine) for another 4 months. The main result was the overall disease activity index (Iran Behçet's disease dynamic activity measure [IBDDAM]). It was shown that with placebo, IBDDAM worsened from 3.17 to $3.63(\mathrm{p}=0.08)$. For colchicine, IBDDAM improved from 3.35 to 2.75 ( $\mathrm{p}<0.0001$ ). Moreover, oral aphthosis, genital aphthosis, pseudo-alveolitis, and erythema nodosum were significantly improved with colchicine, but not with placebo. The difference between the results for men and women was not statistically significant. Thus, colchicine reduced the activity of Behçet's disease [15]. The study by Sun et al. [16] assessed the anti-inflammatory efficacy of the combination of levamisole and colchicine in 64 patients with the mucocutaneous type of Behçet's disease. The concentration of TNF- $\alpha$, IL- 6 , and IL- 8 in the serum was measured. Levamisole was administered at a dose of $50 \mathrm{mg}$ twice daily for patients with $30-50 \mathrm{~kg}$ of body weight, or at a dose of $50 \mathrm{mg}$ 3 times daily for patients with $50-80 \mathrm{~kg}$ of body weight for 3 consecutive days at the beginning of each 2-week interval. Colchicine was administered at a dose of $0.5 \mathrm{mg}$ once or twice daily according to the severity of the disease. It has been shown 
that in 43 patients with serum TNF- $\alpha$, IL- 6 , and IL-8 levels above the upper limit of normal, treatment with levamisole and colchicine for $0.5-11.5$ months statistically significantly decreased levels of these proteins $(\mathrm{p}<0.001)$. Thus, treatment with levamisole and colchicine may result in a significant decrease in the level of IL-6, IL-8, or TNF- $\alpha$ in the serum in patients with the mucocutaneous type of Behçet's disease [16].

\section{Colchicine in the treatment of cardiovascular diseases}

\section{Pericarditis, post-pericardiotomy syndrome, and postoperative AF}

A meta-analysis of 17 prospective clinical trials conducted by Papageorgiou et al. [17] assessed the effect of colchicine on the prevention and treatment of cardiovascular diseases (pericarditis, postcoricardiotomy syndrome, and postoperative atrial fibrillation $[\mathrm{AF}]$ recurrence). The meta-analysis included 2082 patients who received colchicine and 1982 controls, with a mean follow-up of 12 months. Colchicine administration was shown to significantly reduce the risk of recurrent pericarditis/postpericardiotomy syndrome (OR $0.37 ; 95 \%$ CI $0.29-0.47 ; p<0.001)$. In addition, it was shown that colchicine treatment significantly reduced the risk of recurrent $\mathrm{AF}$ by as much as $46 \%$ in patients after cardiac surgery or pulmonary vein isolation (OR 0.54; 95\% CI 0.41-0.7; $\mathrm{p}=0.001$ ). Thus, colchicine has been found to be effective in recurrent pericarditis/postpericardiotomy syndrome and recurrent AF after surgery [17].

The results of the above meta-analysis are consistent with those previously obtained by Imazio et al. [18], who conducted a meta-analysis of 5 randomized clinical trials including 795 patients with pericarditis with an average follow-up of 13 months. The effectiveness of colchicine in the primary and secondary prevention of pericarditis was analyzed. Colchicine administration was shown to be associated with a reduced risk of pericarditis during follow-up (relative risk [RR] 0.40; 95\% CI $0.30-0.54 ; p<0.001$ ) [18]. Similar results were obtained by Lennerz et al. [19] in a meta-analysis of 5 randomized clinical trials. These investigators found that treatment with colchicine reduced postoperative $\mathrm{AF}$ by $31 \%$ compared to placebo or usual care (18\% vs. $27 \%$, RR $0.69 ; 95 \%$ CI $0.57-0.84$; $\mathrm{p}=0.0002$ ). The length of hospital stay after cardiac surgery decreased by 1.2 days following use of colchicine $(95 \% \mathrm{CI}$ from -1.89 to $-0.44, \mathrm{p}=0.002$ ) [19]. A meta-analysis of 6 randomized clinical trials by Salih et al. [20] involving 1257 patients also demonstrated the efficacy of colchicine in reducing the risk of post-operative AF (OR 0.52; 95\% CI 0.40-0.68; $\mathrm{p}<0.001$ ) [20]. An interesting randomized, double-blind, placebo-controlled study by Shojaeifard et al. [21] assessed the efficacy of colchicine in the prevention of acute pericarditis (through its influence on constrictive physiology) after cardiac surgery. Patients $(n=160)$ were randomized to receive colchicine at a dose of $1 \mathrm{mg} /$ day from 48 hours before and $0.5 \mathrm{mg}$ twice/ /day for 5 days after surgery. One week after surgery, the incidence of constrictive physiology was reduced in the colchicine group (13\% vs. $23 \%$ ), but the difference was not statistically significant. After 4 weeks of follow-up, 19 (23\%) patients in the placebo group and $9(11 \%)$ in the colchicine group had constrictive physiology, while 2 of 11 patients $(18.2 \%)$ recovered. The difference was statistically significant $(\mathrm{p}=0.038)$. There was no new case of constrictive physiology between weeks 1 and 4 of observation. Thus, the short-term use of colchicine was preventative in reducing constrictive physiology after 1 month of open-heart surgery, but not after a week [21].

In conclusion, it should be stated that colchicine is a safe and effective drug in the prevention of pericarditis and postoperative AF.

Colchicine, together with acetylsalicylic acid (ASA) and non-steroidal anti-inflammatory drugs (NSAID), is the drug of first choice in the treatment of acute pericarditis and to prevent recurrence as an adjunct to ASA/NSAID therapy (class and level of recommendation: IA) [22]. The anti-inflammatory treatment regimen proposed by the European Society of Cardiology (ESC) for acute pericarditis (first-line therapy) is as follows:

- ASA at a dose of 750-1000 mg every 8 hours for 1-2 weeks (decrease doses by $250-500 \mathrm{mg}$ every $1-2$ weeks);

- ibuprofen at a dose of $600 \mathrm{mg}$ every 8 hours for $1-2$ weeks (decrease doses by $200-400 \mathrm{mg}$ every 1-2 weeks);

- colchicine at a dose of $0.5 \mathrm{mg}$ once $(<70 \mathrm{~kg})$ or $0.5 \mathrm{mg}$ b.i.d. ( $\geq 70 \mathrm{~kg}$ ) for 3 months (tapering not mandatory, alternatively $0.5 \mathrm{mg}$ every other day $[<70 \mathrm{~kg}]$ or $0.5 \mathrm{mg}$ once $[\geq 70 \mathrm{~kg}]$ in the last weeks) [22].

The treatment regimen proposed by the ESC for acute recurrent pericarditis (first-line therapy):

- ASA at a dose of 500-1000 mg every 6-8 hours (range 1.5-4 g/day) for weeks-months (decrease doses by 250-500 mg every 1-2 weeks); 
- ibuprofen at a dose of $600 \mathrm{mg}$ every 8 hours (range 1200-2400 mg) for weeks-months (decrease doses by $200-400 \mathrm{mg}$ every $1-2$ weeks);

- indomethacin at a dose of 25-50 mg every 8 hours (start at lower end of dosing range and titrate upward to avoid headache and dizziness) for weeks-months (decrease doses by $25 \mathrm{mg}$ every $1-2$ weeks);

- colchicine at a dose of $0.5 \mathrm{mg}$ twice or $0.5 \mathrm{mg}$ daily for patients weighing $<70 \mathrm{~kg}$ or intolerant of higher doses for at least 6 months (tapering not necessary, alternatively $0.5 \mathrm{mg}$ every other day $[<70 \mathrm{~kg}]$ or $0.5 \mathrm{mg}$ once [ $\geq 70 \mathrm{~kg}]$ in the last weeks) [22].

It is also worth mentioning that the treatment of pericarditis and its recurrences in patients with systemic lupus erythematosus with colchicine in a study by Morel et al. [23], involving 10 patients, was effective and safe.

\section{Secondary cardiovascular prevention and in-stent restenosis}

The interest in colchicine in the treatment of CAD is justified by its anti-inflammatory [24, $25]$ and anti-atherosclerotic effects [26, 27]. It was found that monthly therapy with colchicine at a dose of $0.5 \mathrm{mg} /$ day led to a decrease in the concentration of inflammatory markers in the blood in patients with chronic CAD [24]. In a randomized and controlled study by Martínez et al. [25] involving 40 patients with acute coronary syndrome (ACS) and 10 patients with stable coronary disease, the effect of colchicine administration on the immune profile of the patients was assessed. Subjects were randomized to receive oral colchicine $(1 \mathrm{mg}$ dose followed by $0.5 \mathrm{mg}$ an hour later) or no colchicine 6 to 24 hours prior to cardiac catheterization. A rapid and significant reduction in the production of pro-inflammatory cytokines in the heart, such as IL-1 $\beta$, IL-6, and IL-18, was demonstrated [25]. Administration of colchicine at a low dose to patients with ACS led to the stabilization of atherosclerotic plaque in the coronary vessels [26]. Moreover, colchicine significantly reduces the local production of chemotactic factors such as chemokine ligand 2 (CCL2), C-X3-C motif chemokine ligand 1 (CX3CL1), and (slightly) chemokine ligand 5 (CCL5) in patients with ACS [27].

The efficacy of adding colchicine to therapy in secondary cardiovascular prevention in patients with CAD was the subject of a meta-analysis of 4 randomized clinical trials conducted by Samuel et al. [28]. The meta-analysis included 11,546 patients with stable coronary disease or ACS, who were administered colchicine $(\mathrm{n}=5774$, dose $0.5 \mathrm{mg} /$ /day) or placebo/no colchicine $(\mathrm{n}=5820)$. It was shown that compared to placebo or no colchicine, colchicine was associated with a statistically significant reduction in myocardial infarction (MI) (hazard ratio [HR] 0.62 ; 95\% CI 0.36-0.88; $p<0.05)$, ischemic stroke (HR $0.38 ; 95 \%$ CI $0.13-0.63 ; \mathrm{p}<0.05$ ) and the urgent need for coronary revascularization (HR 0.56; 95\% CI 0.30-0.82; p < 0.05). However, no statistically significant effect of colchicine administration was demonstrated on reduction of the risk of cardiovascular mortality (HR $0.82 ; 95 \% \mathrm{CI}$ 0.46-1.18), deep vein thrombosis, or pulmonary embolism (HR 1.13; 95\% CI 0.43-1.84). The effect of colchicine administration on the risk of AF was at the borderline of statistical significance (HR 0.86 ; 95\% CI 0.67-1.04). Thus, in secondary cardiovascular prophylaxis, the addition of a low dose of colchicine to standard treatment reduces the incidence of major cardiovascular events, except for cardiovascular mortality, compared to standard therapy alone [28].

The randomized, double-blind, placebo-controlled study COLCOT (Colchicine Cardiovascular Outcomes Trial) conducted by Tardif et al. [29], involving 4745 patients recruited within 30 days of MI, assessed the efficacy of colchicine in secondary cardiovascular prevention. Patients were randomized to receive either low-dose colchicine $(0.5 \mathrm{mg} /$ day; $\mathrm{n}=2366)$ or placebo $(\mathrm{n}=2370)$. A statistically significant $50 \%$ reduction in the risk of urgent hospitalization for angina leading to coronary revascularization was demonstrated (HR 0.50; 95\% CI 0.31-0.81) and the risk of stroke (HR 0.26 ; 95\% CI $0.10-0.70$ ). There was also a reduction in the risk of death from cardiovascular causes (HR 0.84; 95\% CI 0.46-1.52), the risk of sudden cardiac arrest (HR $0.83 ; 95 \% \mathrm{CI}$ 0.25-2.73) and the risk of recurrent MI (HR 0.91; 95\% CI 0.68-1.21) [29]. In further analyses of the studied group of patients it was shown that the greatest benefits in terms of secondary cardiovascular prevention were achieved by those patients who received colchicine within the first 3 days after the onset of MI [30]. In the randomized, double-blind, placebo-controlled study, LoDoCo2 (Low-Dose Colchicine-2), conducted by Nidorf et al. [31] and involving 5522 patients with chronic coronary disease, the effectiveness of colchicine administration on the risk of cardiovascular events was analyzed. Patients were administered either $0.5 \mathrm{mg}$ of colchicine once daily $(\mathrm{n}=2762)$ or placebo $(\mathrm{n}=2760)$. The observation time was 


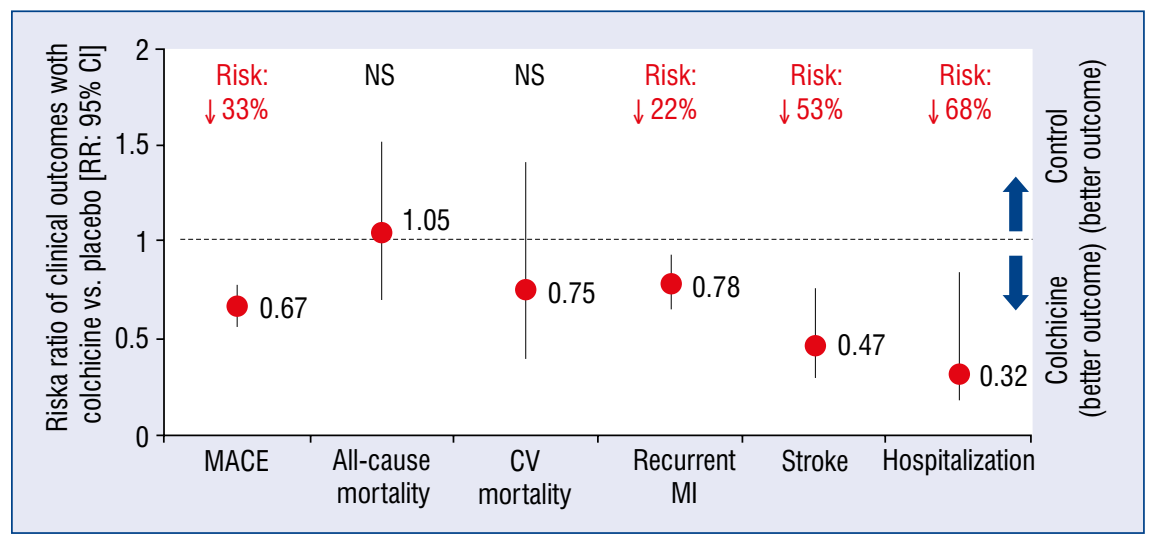

Figure 2. Risk ratios of clinical outcomes with colchicine versus placebo. Based on [32]; $\mathrm{RR}$ - relative risk; $\mathrm{Cl}$ - confidence interval; MACE — major adverse cardiac events; CV — cardiovascular; MI — myocardial infraction; NS — not significant.

28.6 months. The primary endpoint (cardiovascular death, MI, ischemic stroke, or ischemia-driven coronary revascularization) in the colchicine group was reduced by $31 \%$ (HR $0.69 ; 95 \%$ CI $0.57-0.83$; $\mathrm{p}<0.001)$ [31].

The most recent meta-analysis of 12 randomized clinical trials by Bytyçi et al. [32] summarized knowledge on the efficacy of colchicine in patients with CAD (colchicine: $\mathrm{n}=6351$; placebo: $\mathrm{n}=6722$ ). The mean follow-up was 22.5 months. The risk of major adverse cardiac events, all-cause death, cardiovascular death, recurrent myocardial infraction, stroke, and hospitalization were analyzed. The results of this meta-analysis are shown in Figure 2 [32]. The authors of the meta-analysis indicate that colchicine appears to be a promising therapeutic option for effective prevention of cardiovascular events. The effect of colchicine on cardiovascular and all-cause mortality deserves more research, especially long-term [32].

To sum up, colchicine administered at a dose of $0.5 \mathrm{mg}$ /day shows a beneficial effect in the secondary prevention of cardiovascular disease [33]. However, it should be mentioned that there is no recommendation on the use of colchicine in the ESC and Canadian Cardiovascular Society (CCS) guidelines for ST-segment elevation MI/non-ST segment elevation MI (STEMI/NSTEMI), which still limits its use in secondary prevention.

A meta-analysis of 9 randomized clinical trials conducted by Masson et al. [34], including 6630 patients at high cardiovascular risk, analyzed the effect of colchicine administration on the risk of stroke. In this study, 3359 subjects were allocated to receive colchicine while 3271 subjects were allocated to the respective control arms. The incidence of stroke was lower in the colchicine group compared to the placebo group (OR 33; 95\% CI 15-70). Thus, it was found that colchicine significantly reduces the risk of stroke in patients at high cardiovascular risk [34]. In the previously cited meta-analysis by Bytyçi et al. [32] it was also shown that the use of colchicine reduced the risk of stroke (Fig. 2).

In-stent restenosis is a phenomenon sometimes observed after angioplasty procedures involving the relapse of stenosis in the artery being treated. The incidence of restenosis after percutaneous coronary intervention $(\mathrm{PCI})$ is approximately $8 \%$ at 1 -year follow-up. Risk factors $(\mathrm{p}<0.05)$ for restenosis after PCI include the following: postoperative hypersensitive CRP levels (OR 2.309; 95\% CI $1.579-3.375 \mathrm{mg} / \mathrm{L}$ ), postoperative homocysteine levels (OR 2.202; 95\% CI 1.268-3.826 $\mu \mathrm{mol} / \mathrm{L}$ ), history of diabetes (OR 1.955; 95\% CI 1.272-3.003), coronary bifurcation lesions (OR 3.785; 95\% CI 2.246-6.377), and stent length (OR 1.269; 95\% CI 1.179-1.365 mm) [35]. The use of modern drug-eluting stents (DES) and drug-eluting balloons (DEB) in the treatment of CAD significantly reduced the incidence of restenosis (which is one of the major complications associated with bare metal stents) [36]. Considering the important role of the inflammatory process in the pathogenesis of restenosis [37], it seems that the use of colchicine should be an effective method of preventing this complication.

In a meta-analysis conducted by Papageorgiou et al. [17] colchicine administration was not shown to reduce the risk of in-stent restenosis (OR 0.61; 95\% CI $0.24-1.57 ; \mathrm{p}=0.31)$. In a randomized, placebo-controlled study, Deftereos et al. [38] 
analyzed the effect of colchicine administration on the incidence of in-stent restenosis in patients with diabetes and a contraindication to DES implantation $(n=196)$. Patients were randomized to receive colchicine at a dose of $0.5 \mathrm{mg}$ twice daily or placebo for 6 months. It was shown that the frequency of in-stent restenosis was $16 \%$ in the colchicine group and $33 \%$ in the control group (OR 0.38 ; 95\% CI $0.18-0.79 ; \mathrm{p}=0.007)$. The lumen area loss was $1.6 \mathrm{~mm}^{2}$ (interquartile range: 1.0 to $2.9 \mathrm{~mm}^{2}$ ) in patients treated with colchicine and $2.9 \mathrm{~mm}^{2}$ (interquartile range: 1.4 to $4.8 \mathrm{~mm}^{2}$ ) in the control group $(\mathrm{p}=0.002)$. The use of colchicine in diabetic patients after PCI with a metal stent is associated with less neointimal hyperplasia and a reduced incidence of in-stent restenosis [38]. A recently published meta-analysis of 10 studies by Tien et al. [39] showed that the use of colchicine significantly reduced the risk of restenosis after PCI (OR 0.46; 95\% CI 0.23-0.92).

\section{Colchicine in the treatment of COVID-19}

The results of experimental studies have shown that the NLRP3 inflammasome can be activated and triggered by various SARS-CoV-2 proteins, and it may then be involved in the development of acute respiratory distress syndrome (ARDS), a complication of coronavirus disease 2019 (COVID-19). Colchicine, as an important inhibitor of the NLRP3 inflammasome, may be used in the treatment of COVID-19 [8, 40, 41]. In an experimental study involving rats with oleic acid ARDS, the efficacy of colchicine in preventing lung damage was investigated. Rats were administered colchicine at a dose of $1 \mathrm{mg} / \mathrm{kg}$ body weight or placebo for 3 days prior to induction of ARDS. Four hours later, tests were performed, and it was shown that colchicine reduced the histological area of lung damage by $61 \%$, reduced pulmonary edema, improved oxygenation of lung tissue by increasing $\mathrm{PaO}_{2} / \mathrm{FiO}_{2}$ from $66 \pm 13 \mathrm{mmHg}$ (mean $\pm \mathrm{SEM}$ ) to $246 \pm 45$ $\mathrm{mmHg}$, and decreased $\mathrm{pCO}_{2}$ and respiratory acidosis. In addition, colchicine decreased pulmonary neutrophil recruitment and activation of circulating leukocytes. The researchers concluded that colchicine significantly reduced lung damage in the experimental ARDS model [42]. In a clinical trial conducted by Fiorucci et al. [43] involving 30 patients with mild to moderate idiopathic pulmonary fibrosis, the effects of prednisone $(n=11$; dose $1 \mathrm{mg} / \mathrm{kg}$ bw/day) or prednisone + cyclophosphamide ( $\mathrm{n}=9$; dose $0.5 \mathrm{mg} / \mathrm{kg}$ bw/day and $100 \mathrm{mg} /$ day) or prednisone + colchicine $(\mathrm{n}=10$; dose of $0.5 \mathrm{mg} / \mathrm{kg}$ bw/day and $1 \mathrm{mg} /$ day, respectively) for the clinical course of the disease were assessed. Clinical parameters were assessed before treatment and at 6 -month intervals for 18 months. Side effects and 3-year survival were also studied. None of the regimens was shown to be able to influence the course of idiopathic pulmonary fibrosis. However, treatment with colchicine with prednisone resulted in fewer side effects, and the reassessment parameters showed a significant reduction in dyspnea $(\mathrm{p}<0.01)$. There were no significant differences in survival between the 3 groups [43].

In an interesting clinical study by Scarsi et al. [44], involving 262 patients with COVID-19, the effectiveness of colchicine $(n=122)$ was assessed in comparison with standard therapy $(\mathrm{n}=140)$. Standard COVID-19 therapy included hydroxychloroquine and/or intravenous dexamethasone and/or lopinavir/ritonavir. Antiviral drugs were discontinued in the colchicine $1 \mathrm{mg} /$ day group due to potential drug interactions. It was shown that patients with COVID-19 receiving colchicine had a reduced mortality on the $21^{\text {st }}$ day of observation compared to those receiving standard therapy (63.6\% vs. $84.2 \% ; p=0.001)$. The results of this promising study indicate that administering colchicine to patients with COVID-19 is justified and may have potential benefits [44]. In a prospective, randomized, controlled study conducted by Deftereos et al. [45], involving 105 patients with COVID-19, the effect of adding colchicine to standard therapy on the concentration of cardiac and inflammatory biomarkers and the course of COVID-19 was assessed. The patients were divided into a group receiving standard therapy $(n=50)$ and a group additionally receiving colchicine $(n=55)$ for standard therapy. Colchicine was administered according to the following schedule: $1.5 \mathrm{mg}$ loading dose followed by $0.5 \mathrm{mg} 60 \mathrm{~min}$ later and maintenance doses $0.5 \mathrm{mg}$ twice daily along with standard treatment for up to 3 weeks. Standard treatments mainly consisted of chloroquine, hydroxychloroquine, or azithromycin, as well as ritonavir, lopinavir, or tocilizumab. It was shown that patients who received colchicine had a statistically significantly longer time to clinical deterioration. There was no reduction in mortality in the studied COVID-19 patients. There were no significant differences in the levels of highly sensitive cardiac troponin or CRP. Thus, it seems that colchicine may improve the prognosis of COVID-19 patients [45]. In a prospective randomized, double-blind clinical trial conducted by Salehzadeh et al. [46], the effect of colchicine administration on the course of the disease (symptom 
course, hospitalization time, incidence of other diseases) was assessed in 100 patients with COVID-19. The subjects were randomized to a group receiving hydroxychloroquine or a group receiving hydroxychloroquine + colchicine. Colchicine was used at a dose of $1 \mathrm{mg} /$ day for 6 days. It was shown that the compared groups differed statistically significantly in terms of hospitalization time, amounting to 8.12 days in the control group vs. 6.28 days in the study group $(\mathrm{p}=0.001)$. Moreover, in patients with COVID-19 receiving colchicine, the incidence of fever was significantly lower than in the control group ( $2 \%$ vs. $22 \%, \mathrm{p}=0.02)$. Thus, it seems that adding colchicine to COVID-19 treatment may limit the severity of the disease and the time of length of hospital stay [46].

The randomized, double-blind, placebo-controlled clinical trial COL-CORONA by Tardif et al. [47], involving 4159 non-hospitalized patients with COVID-19 (polymerase chain reaction [PCR] confirmed) at high risk of severe disease assessed the efficacy of colchicine versus placebo. Colchicine was administered at a dose of $0.5 \mathrm{mg}$ orally twice daily for the first 3 days and then once daily for the next 27 days. Colchicine use was found to reduce hospitalizations by $25 \%$ (OR 0.75 ; 95\% CI $0.57-0.99$ ), need for mechanical ventilation by $50 \%$ (OR $0.50 ; 95 \%$ CI $0.23-1.07$ ), and the mortality rate by $44 \%$ (OR $0.56 ; 95 \% \mathrm{CI}$ $0.19-1.66)$. In the group of patients receiving colchicine, the most common adverse reaction was gastrointestinal complaints (23.9\% vs. $14.8 \%)$. The results of this very promising study may be a breakthrough in the outpatient treatment of COVID-19 patients [47].

The recently published COLORIT study (COLchicine versus Ruxolitinib and Secukinumab in Open-label Prospective Randomized Trial in Patients with COVID-19) indicated the benefits of the following treatment regimen: $1 \mathrm{mg}$ of colchicine for 1-3 days, then $0.5 \mathrm{mg}$ for 2 weeks as an effective anti-inflammatory treatment for COVID-19. This treatment turned out to be more effective than the administration of expensive anticytokine drugs: ruxolitinib and secukinumab. More aggressive protocols used a loading dose of $1.5 \mathrm{mg}$ of colchicine, an additional dose of $0.5 \mathrm{mg}$ an hour later, and then dosing of $2 \times 0.5 \mathrm{mg}$ daily for 3 weeks [48].

Concerns about the impact of chronic diseases and medications on the risk of SARS-CoV-2 infection and the severity of COVID-19 prompted Haslak et al. [49] to conduct a study involving 404 sick children with AIDS. Based on the epidemiological interview and retrospective analysis of the medical records of the respondents, it was found that during the COVID-19 pandemic, 375 patients were treated with colchicine and 48 with biological drugs. Twenty-four patients were admitted to the hospital with suspected SARS-CoV-2 infection, and 7 of them were confirmed. All patients recovered and no serious complications were found. The researchers conclude that pediatric AIDS patients treated biologically with colchicine may not be at increased risk of either SARS-CoV-2 infection or severe COVID-19 [49].

The results of a meta-analysis of studies assessing the impact of colchicine on the prognosis of patients with COVID-19 are presented in Table 1 $[4,50-55]$.

Currently, several clinical trials are underway to assess the efficacy and safety of colchicine in the treatment of COVID-19 (ClinicalTrials.gov).

Overall, the results of studies and metaanalyses indicate that colchicine may be effective in treating patients with COVID-19.

\section{Colchicine in the treatment of other diseases}

\section{Familial Mediterranean fever}

The therapeutic efficacy of colchicine was assessed in the double-blind, placebo-controlled study by Dinarello et al. [56], involving 11 patients with FMF. This study showed high effectiveness of colchicine in reducing the number of attacks of the disease $(\mathrm{p}<0.001)$ compared to placebo.

Resistance to orally administered colchicine is observed in a proportion of patients with FMF. The pathomechanism of this resistance is unknown, but it was found that these patients had lower concentrations of colchicine in mononuclear cells [57]. In short-term (12 weeks) studies of intravenous colchicine administration in patients with FMF refractory to oral administration, good efficacy and effectiveness have been demonstrated [58, 59]. The study by Grossman et al. [60] evaluated the safety and efficacy of long-term intravenous colchicine administration in patients with FMF refractory to this drug administered orally. The study included 15 patients with frequent attacks of FMF, despite the maximum tolerated dose of oral colchicine (2-3 mg/day), who were treated with weekly intravenous injections of $1 \mathrm{mg}$ of colchicine for at least 12 months. Treatment effectiveness was based on changes in the frequency, duration, and severity of FMF attacks. Safety was assessed on the basis of adverse events. The mean duration of treatment with intravenous colchicine was $5.16 \pm$ 


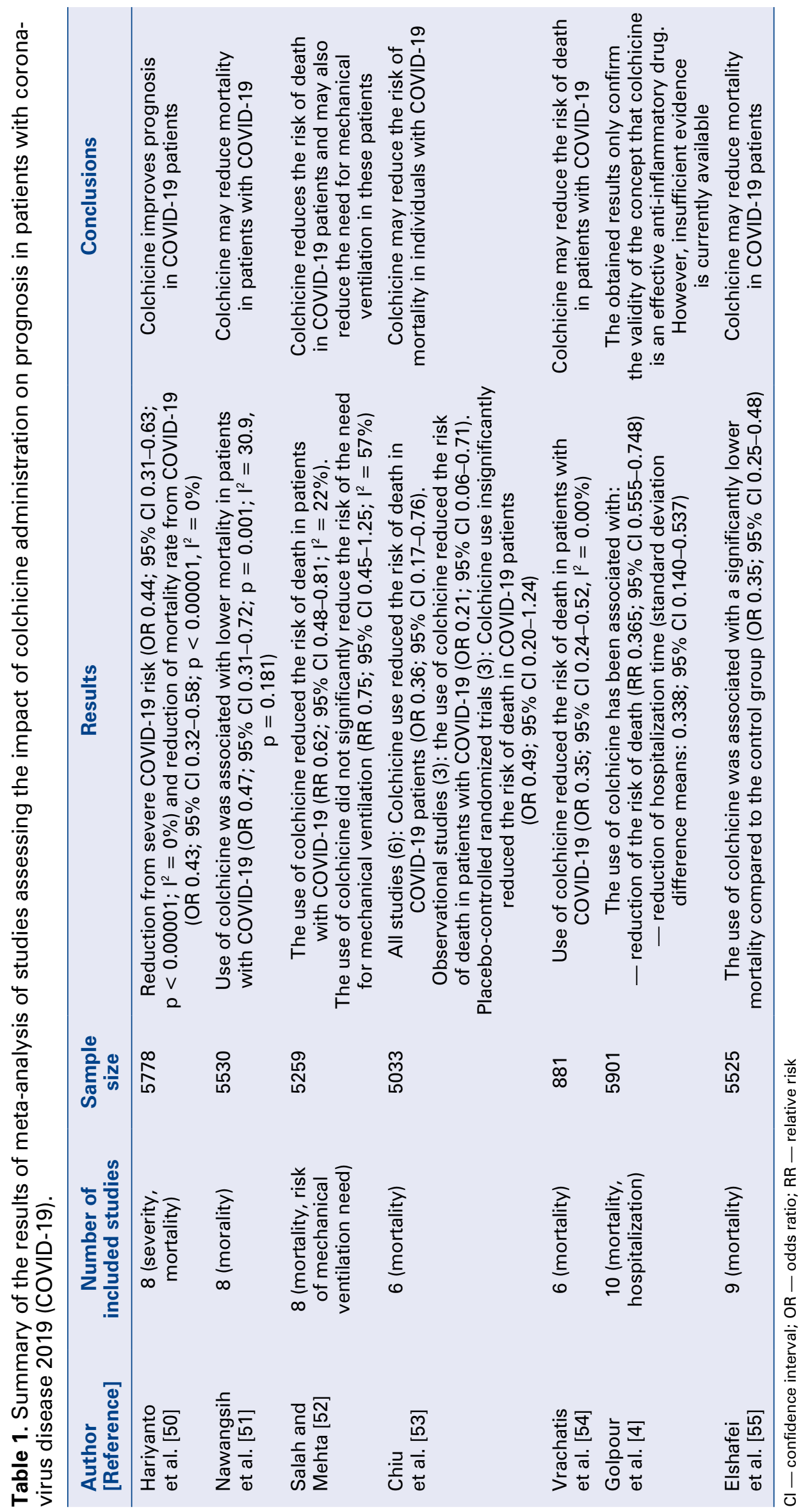




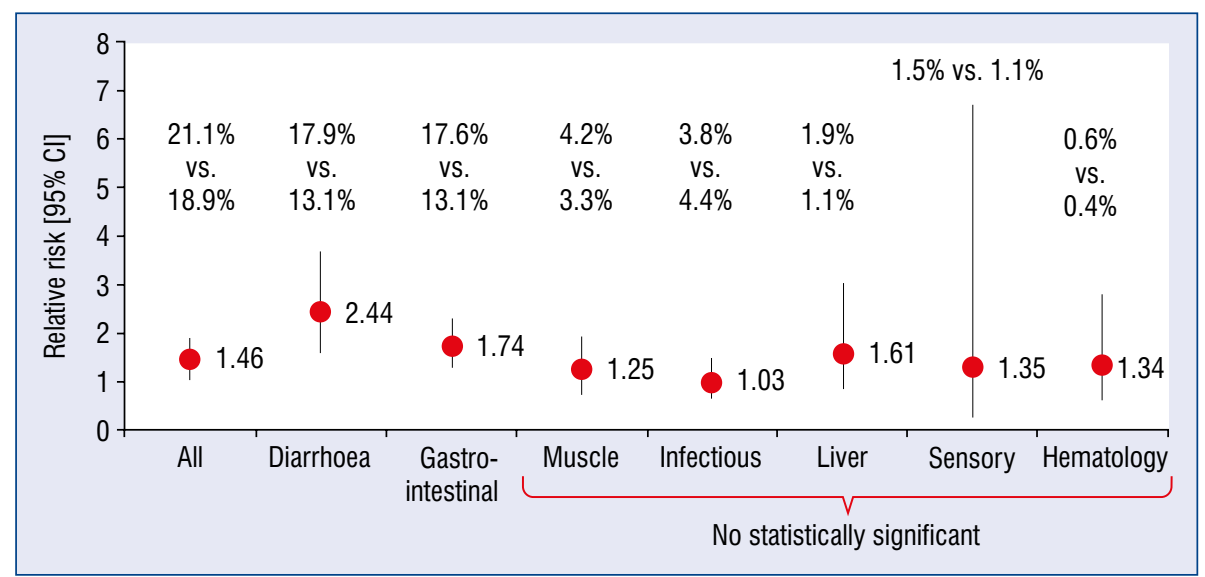

Figure 3. The incidence and relative risk of adverse events in patients using colchicine compared to placebo and comparator drugs. Gastrointestinal included: diarrhea, nausea, vomiting, abdominal pain, loss of appetite, gas, constipation, tarry stools, and peptic ulcers; muscle included: myalgia, muscle cramps, elevated creatine phosphokinase and muscle weakness; infectious included: urinary tract infection, parotiditis, shingles, upper respiratory tract infection, nasopharyngitis and sinus congestion; liver included: increased liver enzymes, hepatitis, hepatotoxicity, and hepatic abnormalities; sensory included: dysesthesia in the legs and paresthesia; hematology included: anemia, bone marrow toxicity, leukopenia, and purpura. Based on [63]; $\mathrm{Cl}$ - confidence interval.

\pm 2.85 years. A decrease was observed in the mean monthly indexes of abdominal attacks (from $5.6 \pm$ \pm 3.7 to $1.9 \pm 3.3, \mathrm{p}=0.0009$ ), joint attacks (from $6.5 \pm 5.1$ to $1,6 \pm 1.6, \mathrm{p}=0.01)$, and total attacks (from $22.3 \pm 16.2$ to $7.4 \pm 5.7, \mathrm{p}=0.002$ ). The incidence of adverse events was low and mainly related to the gastrointestinal tract. No serious adverse events have been reported. Thus, long-term treatment with intravenous colchicine in patients who do not respond to oral colchicine treatment is effective and safe [60].

Overall, administration of oral or intravenous colchicine is effective and safe in patients with FMF.

Colchicine is also effective in the treatment of chronic urticaria, as well as PFAPA syndrome (periodic fever, aphthous stomatitis, pharyngitis, and cervical adenitis) [61, 62].

\section{Safety of colchicine use}

Oral preparation of colchicine is well absorbed from the gastrointestinal tract, reaching the maximum concentration in the blood within 1 hour. $30-50 \%$ of the drug is bound to plasma proteins, and it penetrates into tissues (leukocytes, kidneys, liver, spleen). Colchicine is partially acetylated in the liver and then slowly metabolized in other tissues. It is mainly excreted in the feces, and 10-20\% in the urine. During the use of the drug, its accumulation in tissues occurs. Only $10 \%$ of the drug is excreted within 24 hours of taking a single dose; excretion of the active substance may continue for more than 10 days after the end of treatment. The half-life of the drug (T1/2) in people with normal renal function is 4.4 hours, and 18.8 hours in people with renal insufficiency [2].

The safety of colchicine in various diseases was assessed in a meta-analysis of 35 randomized clinical trials by Stewart et al. [63] published in 2020, including 8659 patients. Subjects were assigned to receive colchicine $(\mathrm{n}=4225)$, placebo $(n=3956)$, or comparator $(n=411)$. The most common diseases in which colchicine was administered were gout, liver cirrhosis, and acute pericarditis. The percentage of patients taking colchicine with any adverse event was $21.1 \%$ (95\% CI 19.9-22.4\%), while in the reference groups it was $18.9 \%$ (95\% CI 17.7-20.1\%). The meta-analysis showed that the overall estimated relative risk for any adverse event in patients using colchicine compared to the reference groups was 1.46 (95\% CI 1.20-1.77, $\mathrm{p}<0.001)$. The most common adverse events were diarrhea and gastrointestinal disorders (Fig. 3). The subgroup analysis showed that patients with liver disease had the highest relative risk of any adverse event (RR 5.92; 95\% CI 2.08-16.82). However, no statistically significant differences in the RR of adverse events were found between patients with various diseases who used colchicine. Moreover, no statistical significance in relative risk of any adverse events was demonstrated at different times 
Table 2. Safety of colchicine in pregnancy in women with familial Mediterranean fever (FMF) and in general pregnancy women. Based on [64].

\begin{tabular}{|c|c|c|}
\hline Parameter & FMF women exposed to colchicine & All women exposed to colchicine \\
\hline Miscarriage & $\begin{array}{c}\text { OR } 0.69(95 \% \mathrm{Cl} 0.43 \text { to } 1.11) \\
\mathrm{p}=0.12\end{array}$ & $\begin{array}{c}\text { OR } 0.65(95 \% \mathrm{Cl} 0.45 \text { to } 0.93) \\
p=0.02\end{array}$ \\
\hline Major malformations & $\begin{array}{c}\text { OR } 0.59(95 \% \mathrm{Cl} 0.12 \text { to } 2.93) \\
\mathrm{p}=0.52\end{array}$ & $\begin{array}{c}\text { OR } 1.08(95 \% \mathrm{Cl} 0.56 \text { to } 2.07) \\
\mathrm{p}=0.82\end{array}$ \\
\hline Pre-term birth & No data & $\begin{array}{c}\text { OR } 2.48(95 \% \mathrm{Cl} 1.65 \text { to } 3.71) \\
p<0.001\end{array}$ \\
\hline Cesarean section & $\begin{array}{c}\text { OR } 1.61(95 \% \mathrm{Cl} 0.65 \text { to } 4.03) \\
p=0.31\end{array}$ & $\begin{array}{c}\text { OR } 1.47(95 \% \mathrm{Cl} 0.96 \text { to } 2.26) \\
p=0.07\end{array}$ \\
\hline Gestational age [weeks] & No data & $\begin{array}{c}\mathrm{MD}-1.00(95 \% \mathrm{Cl}-1.05 \text { to }-0.95) \\
\mathrm{p}<0.001\end{array}$ \\
\hline Birthweight [g] & $\begin{array}{c}\mathrm{MD}-96.72(95 \% \mathrm{Cl}-218.90 \text { to } 25.46) \\
\mathrm{p}=0.12\end{array}$ & $\begin{array}{c}\mathrm{MD}-209.62(95 \% \mathrm{Cl}-381.58 \text { to }-37.66) \text {, } \\
\mathrm{p}=0.02\end{array}$ \\
\hline
\end{tabular}

$\mathrm{OR}$ - odds ratio; $\mathrm{MD}$ - mean difference

of colchicine intake and at different doses $(<50 \mathrm{mg}$; 50 to $<100 \mathrm{mg} ; \geq 100$ to $300 \mathrm{mg}$; and $>600 \mathrm{mg}$ ). No adverse event was found to be related to the patient's death [63]. Thus, colchicine increases the incidence of diarrhea and gastrointestinal adverse events but does not increase the incidence of increased liver enzymes, hepatitis, hepatotoxicity and hepatic abnormalities, dysesthesia in the legs and paresthesia, muscle symptoms (myalgia, muscle cramps, elevated creatine phosphokinase and muscle weakness), infections (urinary tract infection, parotiditis, shingles, upper respiratory tract infection, nasopharyngitis and sinus congestion), or hematological disorders (anemia, bone marrow toxicity, leukopenia and purple). Colchicine also does not increase mortality [63]. The results of this meta-analysis indicate that colchicine is a safe and well-tolerated drug.

Another clinically important concern is the safety of colchicine use in pregnant women. This issue was the subject of a meta-analysis of 4 clinical trials conducted by Indraratna et al. [64], covering 2125 pregnant women. The effect of colchicine intake $(\mathrm{n}=550)$ on the risk of miscarriage and fetal malformation was assessed compared to women who did not take colchicine $(n=1575)$. The indications for the use of colchicine were FMF, Behçet's disease, and others. In the analyzed studies, the daily dose of colchicine was $1-2 \mathrm{mg}$. In the group of women receiving colchicine due to FMF, there was no statistically significant effect of taking colchicine during pregnancy on the risk of miscarriage, fetal malformation, cesarean section, and reduced birth weight (Table 2). Interestingly, the analysis of all women taking colchicine (regardless of the indication for its use) showed a statistically significant reduction in the risk of miscarriage, an increased risk of premature delivery, a reduction in the gestational age and a reduction in birth weight (Table 2). Thus, treatment with colchicine did not significantly increase the incidence of fetal malformations or abortions during pregnancy. The results of this meta-analysis provide clinically significant information that supports the conclusion that colchicine treatment should not be discontinued in the case of FMF during pregnancy [64].

The safety of colchicine may be limited by the presence of contraindications to its use and interactions with other drugs $[65,66]$. Colchicine is metabolized by cytochrome P450 3A4 (CYP3A4) and P-glycoprotein; therefore, the use of drugs that are also substrates for these enzymes may result in lethal adverse effects. Hence, it is important to ask patients if they are using colchicine before prescribing any other medications. The study by Imai et al. [67] assessed the number of prescribed prescriptions for colchicine in patients who were taking drugs that could interact with it at the same time. The study included 3302 patients who regularly take colchicine. Based on the analysis of prescriptions for other drugs issued to these patients, it was found that $43(1.3 \%)$ of them were taking drugs that were strong inhibitors of CYP3A4 or P-glycoprotein (clarithromycin, cyclosporin and itraconazole). Of these 43 patients, 11 had renal and/or hepatic impairment at baseline. Moreover, it was found that patients with Behçet's disease had the highest risk of interaction with colchicine (OR 4.93; 95\% CI 2.12-11.5; $\mathrm{p}<0.001$ ). Among patients with Behçet's disease receiving colchicine and the 
drug interacting with it, $25 \%$ had renal and/or hepatic impairment. Significant drug interactions with colchicine were found in $1 \%$ of patients with gout and Behçet's disease [67]. Thus, in clinical practice, it is always necessary to determine whether a patient taking colchicine has contraindications to its use and to pay attention to other drugs regarding whether they interact with colchicine.

In summary, colchicine is well tolerated and safe, also in pregnant women. In clinical practice, however, the use of colchicine in patients with contraindications and its combination with drugs that may interact with it significantly reduces the safety of this drug.

\section{Conclusions}

Colchicine, a drug with a long tradition, is now experiencing its renaissance. It is a safe and well-tolerated drug. Colchicine is used in rheumatology, cardiology, and neurology, and recently there are more and more data on its effectiveness in the treatment of COVID-19 patients. Colchicine may become an important drug in the early stages of COVID-19 treatment.

\section{Conflict of interest: None declared}

\section{References}

1. Montealegre-Gómez G, Garcia-Botero A, Cantini J, et al. Potential effect of colchicine in the prevention of acute respiratory distress syndrome (ARDS) in patients with Covid-19 infection. Int J Surg Surgical Tech. 2020; 4: 000146, doi: 10.23880/ ijsst-16000146.

2. Dzieciatkowski T, Filipiak KJ. SARS-CoV-2 coronavirus - update 2021 on diagnostic tools, vaccinations, and drugs. PZWL Publishing House, Warsaw 2021.

3. Montealegre-Gómez G, Garavito E, Gómez-López A, et al. Colchicine: A potential therapeutic tool against COVID-19. Experience of 5 patients. Reumatol Clin. 2021; 17(7): 371-375, doi: 10.1016/j.reuma.2020.05.001, indexed in Pubmed: 32426001.

4. Golpour M, Mousavi T, Alimohammadi M, et al. The effectiveness of Colchicine as an anti-inflammatory drug in the treatment of coronavirus disease 2019: Meta-analysis. Int J Immunopathol Pharmacol. 2021; 35: 20587384211031763, doi: 10.1177/20587384211031763, indexed in Pubmed: 34250834.

5. Mizel SB, Wilson L. Nucleoside transport in mammalian cells. Inhibition by colchicine. Biochemistry. 1972; 11(14): 2573-2578, doi: 10.1021/bi00764a003, indexed in Pubmed: 5065219.

6. Viktorov AV, Yurkiv VA. Albendazole and colchicine modulate LPS-induced secretion of inflammatory mediators by liver macrophages. Bull Exp Biol Med. 2011; 151(6): 683-685, doi: 10.1007/s10517-011-1415-8, indexed in Pubmed: 22485207.

7. Takenouchi T, Iwamaru Y, Sugama S, et al. Lysophospholipids and ATP mutually suppress maturation and release of IL-1 beta in mouse microglial cells using a Rho-dependent pathway. J Immunol. 2008; 180(12): 7827-7839, doi: 10.4049/jimmunol.180.12.7827, indexed in Pubmed: 18523246.

8. Leung YY, Yao Hui LLi, Kraus VB. Colchicine: Update on mechanisms of action and therapeutic uses. Semin Arthritis Rheum. 2015; 45(3): 341-350, doi: 10.1016/j.semarthrit.2015.06.013, indexed in Pubmed: 26228647.

9. Terkeltaub RA, Furst DE, Bennett K, et al. High versus low dosing of oral colchicine for early acute gout flare: Twenty-four-hour outcome of the first multicenter, randomized, double-blind, placebo-controlled, parallel-group, dose-comparison colchicine study. Arthritis Rheum. 2010; 62(4): 1060-1068, doi: 10.1002/ art.27327, indexed in Pubmed: 20131255.

10. Roddy E, Clarkson K, Blagojevic-Bucknall M, et al. Open-label randomised pragmatic trial (CONTACT) comparing naproxen and low-dose colchicine for the treatment of gout flares in primary care. Ann Rheum Dis. 2020; 79(2): 276-284, doi: 10.1136/ annrheumdis-2019-216154, indexed in Pubmed: 31666237.

11. Aran S, Malekzadeh S, Seifirad S. A double-blind randomized controlled trial appraising the symptom-modifying effects of colchicine on osteoarthritis of the knee. Clin Exp Rheumatol. 2011; 29(3): 513-518, indexed in Pubmed: 21640042.

12. Erden M, Ediz L, Hız Ö, et al. Effect of Colchicine on Total Antioxidant Capacity, Antioxidant Enzymes and Oxidative Stress Markers in Patients with Knee Osteoarthritis. Int J Clin Med. 2012; 3(5): 377-382, doi: 10.4236/ijcm.2012.35071.

13. Leung YY, Haaland B, Huebner JL, et al. Colchicine lack of effectiveness in symptom and inflammation modification in knee osteoarthritis (COLKOA): a randomized controlled trial. Osteoarthritis Cartilage. 2018; 26(5): 631-640, doi: 10.1016/j. joca.2018.01.026, indexed in Pubmed: 29426008.

14. Restrepo-Escobar M, Carmona-Franceschi M, Gómez JD. Colchicine treatment in adult patients with knee osteoarthritis: Systematic review of the literature. Rev Colomb Reumatol (English Edition). 2017; 24(2): 102-111, doi: 10.1016/j. rcreue.2017.01.002.

15. Davatchi F, Abdollahi BS, Banihashemi AT, et al. Colchicine versus placebo in Behçet's disease: randomized, double-blind, controlled crossover trial. Mod Rheumatol. 2014; 19(5): 542-549, doi: 10.3109/s10165-009-0200-2.

16. Sun A, Wang YP, Chia JS, et al. Treatment with levamisole and colchicine can result in a significant reduction of IL-6, IL-8 or TNFalpha level in patients with mucocutaneous type of Behcet's disease. J Oral Pathol Med. 2009; 38(5): 401-405, doi: 10.1111/j.16000714.2009.00774.x, indexed in Pubmed: 19434815.

17. Papageorgiou N, Briasoulis A, Lazaros G, et al. Colchicine for prevention and treatment of cardiac diseases: A meta-analysis. Cardiovasc Ther. 2017; 35(1): 10-18, doi: 10.1111/17555922.12226, indexed in Pubmed: 27580061.

18. Imazio M, Brucato A, Forno D, et al. Efficacy and safety of colchicine for pericarditis prevention. Systematic review and meta-analysis. Heart. 2012; 98(14): 1078-1082, doi: 10.1136/ heartjnl-2011-301306, indexed in Pubmed: 22442198.

19. Lennerz C, Barman M, Tantawy M, et al. Colchicine for primary prevention of atrial fibrillation after open-heart surgery: Systematic review and meta-analysis. Int J Cardiol. 2017; 249: 127-137, doi: 10.1016/j.ijcard.2017.08.039, indexed in Pubmed: 28918897.

20. Salih M, Smer A, Charnigo R, et al. Colchicine for prevention of post-cardiac procedure atrial fibrillation: Meta-analysis of randomized controlled trials. Int J Cardiol. 2017; 243: 258-262, doi: 10.1016/j.ijcard.2017.04.022, indexed in Pubmed: 28747027. 
21. Shojaeifard M, Pakbaz M, Beheshti R, et al. The effect of colchicine on the echocardiographic constrictive physiology after coronary artery bypass graft surgery. Echocardiography. 2020; 37(3): 399-403, doi: 10.1111/echo.14605, indexed in Pubmed: 32175647.

22. Adler Y, Charron P, Imazio M, et al. 2015 ESC Guidelines for the diagnosis and management of pericardial diseases: The Task Force for the Diagnosis and Management of Pericardial Diseases of the European Society of Cardiology (ESC)Endorsed by: The European Association for Cardio-Thoracic Surgery (EACTS). Eur Heart J. 2015; 36(42): 2921-2964, doi: 10.1093/eurheartj/ ehv318, indexed in Pubmed: 26320112.

23. Morel N, Bonjour M, Le Guern V, et al. Colchicine: a simple and effective treatment for pericarditis in systemic lupus erythematosus? A report of 10 cases. Lupus. 2015; 24(14): 1479-1485, doi: 10.1177/0961203315593169, indexed in Pubmed: 26163661.

24. Fiolet ATL, Silvis MJM, Opstal TSJ, et al. Short-term effect of low-dose colchicine on inflammatory biomarkers, lipids, blood count and renal function in chronic coronary artery disease and elevated high-sensitivity C-reactive protein. PLoS One. 2020; 15(8): e0237665, doi: 10.1371/journal.pone.0237665, indexed in Pubmed: 32866166.

25. Martínez GJ, Robertson S, Barraclough J, et al. Colchicine acutely suppresses local cardiac production of inflammatory cytokines in patients with an acute coronary syndrome. J Am Heart Assoc. 2015; 4(8): e002128, doi: 10.1161/JAHA.115.002128, indexed in Pubmed: 26304941.

26. Vaidya K, Arnott C, Martínez GJ, et al. Colchicine therapy and plaque stabilization in patients with acute coronary syndrome: a CT coronary angiography study. JACC Cardiovasc Imaging. 2018; 11(2 Pt 2): 305-316, doi: 10.1016/j.jcmg.2017.08.013, indexed in Pubmed: 29055633.

27. Tucker B, Kurup R, Barraclough J, et al. Colchicine as a novel therapy for suppressing chemokine production in patients with an acute coronary syndrome: a pilot study. Clin Ther. 2019; 41(10): 2172-2181, doi: 10.1016/j.clinthera.2019.07.015, indexed in Pubmed: 31409556.

28. Samuel M, Tardif JC, Bouabdallaoui N, et al. Colchicine for secondary prevention of cardiovascular disease: a systematic review and meta-analysis of randomized controlled trials. Can J Cardiol. 2021; 37(5): 776-785, doi: 10.1016/j.cjca.2020.10.006, indexed in Pubmed: 33075455.

29. Tardif JC, Kouz S, Waters DD, et al. Efficacy and safety of lowdose colchicine after myocardial infarction. N Engl J Med. 2019; 381(26): 2497-2505, doi: 10.1056/NEJMoa1912388, indexed in Pubmed: 31733140.

30. Bouabdallaoui N, Tardif JC, Waters DD, et al. Time-to-treatment initiation of colchicine and cardiovascular outcomes after myocardial infarction in the Colchicine Cardiovascular Outcomes Trial (COLCOT). Eur Heart J. 2020; 41(42): 4092-4099, doi: 10.1093/eurheartj/ehaa659, indexed in Pubmed: 32860034.

31. Nidorf SM, Fiolet ATL, Mosterd A, et al. Colchicine in patients with chronic coronary disease. N Engl J Med. 2020; 383(19): 1838-1847, doi: 10.1056/NEJMoa2021372, indexed in Pubmed: 32865380.

32. Bytyçi I, Bajraktari G, Penson PE, et al. Efficacy and safety of colchicine in patients with coronary artery disease: A systematic review and meta-analysis of randomized controlled trials. Br J Clin Pharmacol. 2021 [Epub ahead of print], doi: 10.1111/ bcp.15041, indexed in Pubmed: 34409634.

33. Roubille F, Tardif JC. Colchicine for secondary cardiovascular prevention in coronary disease. Circulation. 2020; 142(20):
1901-1904, doi: 10.1161/CIRCULATIONAHA.120.051240, indexed in Pubmed: 33196312.

34. Masson W, Lobo M, Molinero G, et al. Role of colchicine in stroke prevention: an updated meta-analysis. J Stroke Cerebrovasc Dis. 2020; 29(5): 104756, doi: 10.1016/j.jstrokecerebrovasdis.2020.104756, indexed in Pubmed: 32160956.

35. Cheng G, Chang FJ, Wang Yi, et al. Factors influencing stent restenosis after percutaneous coronary intervention in patients with coronary heart disease: a clinical trial based on 1-year follow-up. Med Sci Monit. 2019; 25: 240-247, doi: 10.12659/ MSM.908692, indexed in Pubmed: 30617247.

36. Liu L, Liu B, Ren J, et al. Comparison of drug-eluting balloon versus drug-eluting stent for treatment of coronary artery disease: a meta-analysis of randomized controlled trials. BMC Cardiovasc Disord. 2018; 18(1): 46, doi: 10.1186/s12872-018-0771-y, indexed in Pubmed: 29499651.

37. Demirtas K. Inflammation and In-Stent Restenosis. Angiology. 2018; 69(1): 89, doi: $10.1177 / 0003319717722103$, indexed in Pubmed: 28737071.

38. Deftereos S, Giannopoulos G, Raisakis K, et al. Colchicine treatment for the prevention of bare-metal stent restenosis in diabetic patients. J Am Coll Cardiol. 2013; 61(16): 1679-1685, doi: 10.1016/j.jacc.2013.01.055, indexed in Pubmed: 23500260.

39. Tien YY, Huang HK, Shih MC, et al. Drug repurposing? Cardiovascular effect of colchicine on patients with coronary artery disease: A systematic review and meta-analysis. J Cardiol. 2021; 77(6): 576-582, doi: 10.1016/j.jjcc.2020.11.010, indexed in Pubmed: 33272780 .

40. Ratajczak MZ, Kucia M. SARS-CoV-2 infection and overactivation of Nlrp3 inflammasome as a trigger of cytokine „storm” and risk factor for damage of hematopoietic stem cells. Leukemia. 2020; 34(7): 1726-1729, doi: 10.1038/s41375-020-0887-9, indexed in Pubmed: 32483300.

41. Cocco G, Chu DCC, Pandolfi S. Colchicine in clinical medicine. A guide for internists. Eur J Intern Med. 2010; 21(6): 503-508, doi: 10.1016/j.ejim.2010.09.010, indexed in Pubmed: 21111934.

42. Dupuis J, Sirois MG, Rhéaume E, et al. Colchicine reduces lung injury in experimental acute respiratory distress syndrome. PLoS One. 2020; 15(12): e0242318, doi: 10.1371/journal. pone.0242318, indexed in Pubmed: 33264297.

43. Fiorucci E, Lucantoni G, Paone G, et al. Colchicine, cyclophosphamide and prednisone in the treatment of mild-moderate idiopathic pulmonary fibrosis: comparison of three currently available therapeutic regimens. Eur Rev Med Pharmacol Sci. 2008; 12(2): 105-111, indexed in Pubmed: 18575160.

44. Scarsi M, Piantoni S, Colombo E, et al. Association between treatment with colchicine and improved survival in a single-centre cohort of adult hospitalised patients with COVID-19 pneumonia and acute respiratory distress syndrome. Ann Rheum Dis. 2020; 79(10): 1286-1289, doi: 10.1136/annrheumdis-2020-217712, indexed in Pubmed: 32732245.

45. Deftereos SG, Giannopoulos G, Vrachatis DA, et al. Effect of colchicine vs standard care on cardiac and inflammatory biomarkers and clinical outcomes in patients hospitalized with coronavirus disease 2019: the GRECCO-19 randomized clinical trial. JAMA Netw Open. 2020; 3(6): e2013136, doi: 10.1001/jamanetworkopen.2020.13136, indexed in Pubmed: 32579195.

46. Salehzadeh F, Pourfarzi F, Ataei S. The impact of colchicine on the COVID-19 patients; a clinical trial study. Research Square. 2020, doi: 10.21203/rs.3.rs-69374/v1. 
47. Tardif J, Bouabdallaoui N, L'Allier PL, et al. Efficacy of colchicine in non-hospitalized patients with COVID-19. MedRxiv. 2021: medRxiv, doi: https://doi.org/10.1101/2021.01.26.21250494.

48. Mareev VYu, Orlova YaA, Plisyk AG, et al. Proactive anti-inflammatory therapy with colchicine in the treatment of advanced stages of new coronavirus infection. The first results of the COLORIT study. Kardiologiia. 2021; 61(2): 15-27, doi: 10.18087/ cardio.2021.2.n1560, indexed in Pubmed: 33734043.

49. Haslak F, Yildiz M, Adrovic A, et al. Management of childhoodonset autoinflammatory diseases during the COVID-19 pandemic. Rheumatol Int. 2020; 40(9): 1423-1431, doi: 10.1007/ s00296-020-04645-x, indexed in Pubmed: 32661928.

50. Hariyanto TI, Halim DA, Jodhinata C, et al. Colchicine treatment can improve outcomes of coronavirus disease 2019 (COVID-19): A systematic review and meta-analysis. Clin Exp Pharmacol Physiol. 2021; 48(6): 823-830, doi: 10.1111/1440-1681.13488, indexed in Pubmed: 33719081.

51. Nawangsih E, Kusmala Y, Rakhmat I, et al. Colchicine and mortality in patients with coronavirus disease 2019 (COVID-19) pneumonia: A systematic review, meta-analysis, and metaregression. Int Immunopharmacol. 2021; 96: 107723, doi: 10.1016/j.intimp.2021.107723.

52. Salah HM, Mehta JL. Meta-analysis of the effect of colchicine on mortality and mechanical ventilation in COVID-19. Am J Cardiol. 2021; 145: 170-172, doi: 10.1016/j.amjcard.2021.02.005, indexed in Pubmed: 33617817.

53. Chiu L, Lo CH, Shen M, et al. Colchicine use in patients with COVID-19: a systematic review and meta-analysis. medRxiv. 2021, doi: 10.1101/2021.02.02.21250960.

54. Vrachatis DA, Giannopoulos GV, Giotaki SG, et al. Impact of colchicine on mortality in patients with COVID-19: A meta-analysis. Hellenic J Cardiol. 2021 [Epub ahead of print], doi: 10.1016/j. hjc.2020.11.012, indexed in Pubmed: 33421583.

55. Elshafei MN, El-Bardissy A, Khalil A, et al. Colchicine use might be associated with lower mortality in COVID-19 patients: A meta-analysis. Eur J Clin Invest. 2021; 51(9): e13645, doi: 10.1111/ eci.13645, indexed in Pubmed: 34185313.

56. Dinarello CA, Wolff SM, Goldfinger SE, et al. Colchicine therapy for familial mediterranean fever. A double-blind trial. N Engl J Med. 1974; 291(18): 934-937, doi: 10.1056/ NEJM197410312911804, indexed in Pubmed: 4606353.

57. Lidar M, Scherrmann J, Shinar Y, et al. Colchicine nonresponsiveness in familial mediterranean fever: clinical, genetic, pharmacokinetic, and socioeconomic characterization. Semin Arthritis Rheum. 2004; 33(4): 273-282, doi: 10.1053/s00490172(03)00137-9, indexed in Pubmed: 14978665.
58. Lidar M, Kedem R, Langevitz P, et al. Intravenous colchicine for treatment of patients with familial Mediterranean fever unresponsive to oral colchicine. J Rheumatol. 2003; 30(12): 2620-2623, indexed in Pubmed: 14719203.

59. Rozenbaum M, Boulman N, Feld J, et al. Intravenous colchicine treatment for six months: adjunctive therapy in familial Mediterranean fever (FMF) unresponsive to oral colchicine. Clin Exp Rheumatol. 2009; 27(2 Suppl 53): S105, indexed in Pubmed: 19796546.

60. Grossman C, Farberov I, Feld O, et al. Efficacy and safety of longterm treatment with intravenous colchicine for familial Mediterranean fever (FMF) refractory to oral colchicine. Rheumatol Int. 2019; 39(3): 517-523, doi: 10.1007/s00296-018-04237-w, indexed in Pubmed: 30604205.

61. Criado RFJ, Criado PR, Martins JE, et al. Urticaria unresponsive to antihistaminic treatment: an open study of therapeutic options based on histopathologic features. J Dermatolog Treat. 2008; 19(2): 92-96, doi: 10.1080/09546630701499309, indexed in Pubmed: 18484427.

62. Quintana-Ortega C, Seoane-Reula E, Fernández L, et al. Colchicine treatment in children with periodic fever, aphthous stomatitis, pharyngitis, and cervical adenitis (PFAPA) syndrome: A multicenter study in Spain. Eur J Rheumatol. 2020 [Epub ahead of print], doi: 10.5152/eurjrheum.2020.20102, indexed in Pubmed: 32966191.

63. Stewart S, Yang KC, Atkins K, et al. Adverse events during oral colchicine use: a systematic review and meta-analysis of randomised controlled trials. Arthritis Res Ther. 2020; 22(1): 28, doi: 10.1186/s13075-020-2120-7, indexed in Pubmed: 32054504 .

64. Indraratna PL, Virk S, Gurram D, et al. Use of colchicine in pregnancy: a systematic review and meta-analysis. Rheumatology (Oxford). 2018; 57(2): 382-387, doi: 10.1093/rheumatology/ kex353, indexed in Pubmed: 29029311.

65. Davis MW, Wason S, Digiacinto JL. Colchicine-antimicrobial drug interactions: what pharmacists need to know in treating gout. Consult Pharm. 2013; 28(3): 176-183, doi: 10.4140/ TCP.n.2013.176, indexed in Pubmed: 23462027.

66. Colchicine: serious interactions. Prescrire Int. 2008; 17(96): 151-153, indexed in Pubmed: 19492485.

67. Imai S, Momo K, Kashiwagi H, et al. Prescription of colchicine with other dangerous concomitant medications: a nation-wide survey using the Japanese claims database. Biol Pharm Bull. 2020; 43(10): 1519-1525, doi: 10.1248/bpb.b20-00314, indexed in Pubmed: 32999162. 